\title{
Fallacies in the Historiography of Generative Linguistics
}

\author{
András Kertész ${ }^{1}$ \\ Published online: 10 June 2019 \\ (C) The Author(s) 2019
}

\begin{abstract}
The paper relates two different fields of research: the historiography of generative linguistics and argumentation theory, a central topic of which is the investigation of fallacies. Relating the two fields is a challenge: Since fallacies seem to be at the heart of the historiography of generative linguistics, any thorough evaluation of its present state of the art also involves accounting for fallacies. The paper applies Kertész and Rákosi's p-model of plausible argumentation to a case study on heated discussions in the historiography of generative linguistics. As a result, basic properties of fallacious argumentation are revealed and delimited from plausible argumentation in linguistic historiography. In addition, the paper also draws generalizable conclusions that may affect the historiography of other human sciences as well.
\end{abstract}

Keywords Linguistic historiography · The history of generative linguistics · Fallacy · Plausible argumentation

\section{Introduction}

\subsection{On Fallacies}

There is a provocative relationship between two different fields of research. One is argumentation theory, a central and much debated topic of which is the investigation of fallacies. The other is the historiography of linguistics. In order to motivate the problem which the present paper tackles, let us show briefly how they are related.

The relevance of fallacies is rooted in at least three factors, both in everyday discussions and in scientific inquiry. First, they are deceptive: if they are not noticed, they may effectively convince the hearer or the reader that a mistaken standpoint is correct. Second, if they are noticed, then the opposite effect can be achieved: the charge of fallacious

I am grateful to three anonymous reviewers for their insightful comments on an earlier draft. I am the only person responsible for the shortcomings of the present paper.

András Kertész

andraskertesz@yahoo.de

http://web.t-online.hu/andraskertesz/angol.htm

1 MTA-DE Research Group for Theoretical Linguistics, University of Debrecen, Institute of German Studies, Egyetem tér 1, Debrecen 4032, Hungary 
argumentation is devastating, because it undermines one's position, destroys one's claims and may even be humiliating. Moreover, it is extremely difficult to defend oneself against such a charge, because the defense presupposes at least the precise definition of the fallacy at issue, which is normally anything but straightforward.

In scientific inquiry-because its norms prescribe clarity, precision, transparency, simplicity and the like-fallacies are even more dangerous than in everyday conversation. If they have not been realized, through their deceptiveness, they may in the long run steer research down the wrong track. If they are noticed, the accusation of having committed a fallacy can destroy whole research programs. Therefore, it is a special task to reveal the nature of fallacies in scholarly argumentation.

\subsection{On the Historiography of Generative Linguistics}

The other field is the historiography of generative linguistics. The fact that it is currently a hot topic arises from at least three factors. First, there is a great diversity of approaches which evaluate the history of generative linguistics in substantially different ways; for example, Kertész (2017) analyzed 22 approaches. Second, some of these evaluations apply to different developmental stages of generative linguistics: for example, having triggered a Kuhnian scientific revolution is something associated with Syntactic Structures, Generative Phonology, Aspects of the Theory of Syntax, Government-Binding Theory, and the Minimalist Program. Third, one of the most frequently mentioned characteristics of the heated debates between such views is that "much of this literature also suffers from the widely recognized biases of its authors, whose theoretical commitments color their writing" (Martin-Nielsen 2010: 332; emphasis added). Biases are assumed to be spectacular features of the historiography of generative linguistics, culminating in at times passionate debates and hostile formulations. However, the majority of those approaches which charge others with being biased are themselves biased. ${ }^{1}$

While the first two features of the literature on the history of generative linguistics were discussed at length in Kertész (2017), the present paper will focus on the third one. Our starting point is that although, generally speaking, bias cannot be identified with what the argumentation theoretical literature calls 'fallacies', in specific terms many of the phenomena which are referred to as 'bias' seem to be manifestations of different kinds of fallacies. ${ }^{2}$

\footnotetext{
1 To mention only one example, let us refer to the fact that according to Newmeyer (2014: 242), Nielsen's (2010) claims, which the above quotation is based on, "are all either greatly exaggerated or flat out wrong".

2 In this respect, as a point of departure, we agree with Walton's (1996: 127-128) insight:

"Bias, itself, however, is not a fallacy or a fallacious type of argumentation per se. It is rather a type of attitude that often leads to, and is associated with fallacies. Bias is sometimes harmless, and it is only the harmful type of bias that should be subject to criticism, in the same way that fallacies are subject to criticism as serious failures of argumentation."

By way of illustration of what is meant by bias in the present context, here is a list of examples with respect to the historiography of generative linguistics which Kertész (2017) discussed: the historiographers' bias towards or against the object of investigation (i.e. generative linguistics); the historiographers' bias towards or against Chomsky's personality; the historiographers' bias against one another; historiographical frameworks as tools of legitimizing generative linguistics; the legitimizing interpretation of historical data; circular argumentation as a legitimizing tool. The last is a clear example of bias as the manifestation of a fallacy i.e. that of circular argumentation.
} 


\subsection{The Problems}

Relating the two fields is a challenge: Since fallacies seem to be at the heart of the historiography of generative linguistics, any thorough evaluation of its present state of the art also involves accounting for these fallacies. The scope of the present paper does not allow for a comprehensive analysis of the different types of fallacies that can be found in the historiographical literature. Therefore, we will restrict the exemplification of fallacies in the historiography of generative linguistics to two of the most spectacular types, namely, argumentum ad hominem and false analogy. We raise the following problem:

(P1) Are there fallacies of the types argumentum ad hominem and false analogy in the historiography of generative linguistics, and if so, what are their main characteristics?

The precondition for presenting a solution to $(\mathrm{P} 1)$ is to solve (P2):

(P2) What argumentation theoretical framework can provide a solution to (P1)?

The aim of the present paper is to put forward solutions to (P1) and (P2). We will proceed as follows.

In Sect. 2, we will briefly summarize the central notions of Kertész and Rákosi's (2012) p-model of plausible argumentation that yields a possible solution to (P2). In Sect. 3, we will apply this framework to cases of argumentum ad hominem and false analogy in the historiography of generative linguistics. In Sect. 4, we will draw generalizable conclusions that may apply to other fields of historiography as well and summarize the solution to (P1).

Due to the fierce debates on the history of generative linguistics, before we proceed, it is important to point out that the present paper is not meant to be a contribution to these debates. It is not our aim to take sides for or against the supporters or the opponents of generative linguistics, nor to blame, condemn or attack the scholars whose writings will be quoted or whose names are mentioned in the quotations to be analyzed. The quotations from the historiographical works are to be treated as data that can be made subject to scientific analysis. The present paper is intended to be an impartial, unbiased and balanced contribution to the metatheory of linguistic historiography with implications for scientific history writing in general.

\section{On (P2): The Framework}

\subsection{The p-Model}

\subsubsection{Introductory Remark}

The p-model is a metatheoretical approach to theory formation in linguistics put forward systematically in Kertész and Rákosi (2012). Its main hypothesis says that linguistic theorizing is a process of plausible argumentation. Accordingly, the p-model is not an allembracing approach to argumentation claiming general validity and applicability, but its domain of application is restricted to linguistics. The terms and the tenets it introduces 
have been motivated by foundational problems of linguistic inquiry. It has already been applied to the metatheoretical analysis of many different linguistic theories and problems discussed in theoretical linguistics and the philosophy of linguistics (besides Kertész and Rákosi 2012, see among others Kertész and Rákosi (eds.) 2014b for a collection of such applications).

Below we will recapitulate some of the basic notions of the p-model in a simplified and informal way. ${ }^{3}$ For their detailed and precise introduction, see Kertész and Rákosi (2012), and for a shorter overview Kertész and Rákosi (2014a).

\subsubsection{Plausible Statements}

Most of the statements which researchers maintain about the phenomena they investigate are not true with certainty, but merely plausible to some extent. Such statements are called plausible statements. Plausible statements consist of an information content and a plausibility value (Kertész and Rákosi 2012: 63-79).

The plausibility value of statements is determined by the reliability of the sources they stem from. The plausibility value of the statement $p$ on the basis of the source $S$ is such that ${ }^{4}$ :

$|p|_{S}=1$, if $p$ is true with certainty on the basis of $S$;

(b) $\quad|p|_{S}=0$, if $p$ is of neutral plausibility on the basis of $S$, i.e., if it is neither plausible nor implausible on the basis of this source;

(c) $\quad 0<|p|_{S}<1$, if $p$ is plausible on the basis of $S$;

(d) $\quad 0<|\sim p|_{S}<1$, if $p$ is implausible on the basis of $S$. $^{5}$

There are two kinds of sources (Kertész and Rákosi 2012: 63-70). In the case of direct sources, the plausibility value of the statement at issue is evaluated with respect to the reliability of the source at issue. Such direct sources are, for example, the linguistic intuition of native speakers, statistical data of a corpus, whole publications, real experiments, thought experiments, the authority of a person etc. In the case of indirect sources, the plausibility value of the given statement is rooted the plausibility value of other statements. Typical instances of indirect sources are inferences.

For example, one statement which may be made in the historiography of generative linguistics can be represented like this (see also (28)(b)):

$0<$ IIf a person is biased, then he or she should not be given as much credibility as he or she would have without the bias. $\left.\left.\right|_{S}<1\right]$

\footnotetext{
3 Although the p-model is no logic, in Kertész and Rákosi (2012) the definitions are introduced by the use of a complex set-theoretical and arithmetical notation whose inclusion in the present paper would be beside the point.

${ }^{4}$ Plausibility and (subjective or objective) probability are completely different concepts. Thus, for example, low plausibility values do not mean improbability. Even in such cases the source votes for the given hypothesis, although it provides only a weak argument for its acceptance. If a source is against a hypothesis, then it makes its negation plausible. For details, see Kertész and Rákosi (2012: 66) and Rescher (1976, Chapter IV).

5 ' $\sim$ ' indicates the negation of the statement, and ' $\mathrm{x}<\mathrm{y}$ ' should be read: 'the value of $x$ is lower than the value of $y$ '. These symbols are to be treated as notations and do not constitute a logic.
} 
This statement is plausible i.e. it has a positive plausibility value between 1 (true) and 0 (neutral plausibility). The plausibility value of (2) depends on the reliability of the direct source $S$. This source may be, for example, the authority of a certain historiographer of linguistics.

\subsubsection{Plausible Inferences}

Plausible statements can be used as premises of inferences. Inferences whose conclusion is a plausible statement are called plausible inferences (Kertész and Rákosi 2012: 79-128). In plausible inferences the connection between the statements-i.e. the premises and the conclusion or the clauses which a premise consists of-involves a semantic relation such as causality, analogy, necessary or sufficient condition, part-whole relation, whole-part relation, relevance etc. Since plausible inferences take the content of statements into account, are context-sensitive and not necessarily deductive, the p-model is no logic (see Kertész and Rákosi 2012: 56-85; Kertész 2017: 125). It cannot be interpreted as a formal system broader than logic, either. Its tenets and terms do not constitute a calculus.

There are three types of plausible inferences:

(a) In the first type, the structure of the inference corresponds to the structure of deductively valid inferences, but since it includes at least one premise that is merely plausible instead of being true, its conclusion is not true either, but plausible. This type includes, for example, 'plausible modus ponens', 'plausible modus tollens' etc. For example:

(3) Premises

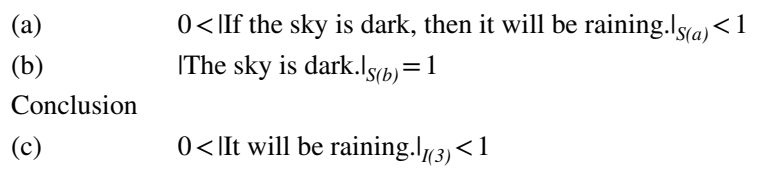

The reason why the first premise cannot be true is that the direct source $S(a)$ rests on an inductive generalization based on personal experiences. Although we cannot state that the first premise is true with certainty, it is legitimate to deem it plausible on the basis of our previous experiences while we know that it may happen that the sky is dark, and it will not be raining. In the case of premise (3)(b), our current sensory experience as a direct source $S(b)$ may be reliable enough in order to deem the statement true. Due to the premise (3)(a), the conclusion in (3)(c) cannot be true, although premise (3)(b) is true and there is a logical consequence relation between the premises and the conclusion. $I(3)$ stands for the indirect source of the conclusion (3)(c) (i.e. the premises).

(b) The main feature of the second type is that although the premises are true, its structure is not valid, because at least one premise that would be needed in order to make the conclusion true is missing. Therefore, the premises of such inferences-which are called enthymematic - may be supplemented by latent background assumptions. Such latent 
background assumptions are needed in order to make the structure of the inference valid. ${ }^{6}$ Consider:

(4) Premises
(a)
IAndrew's head is big. $\left.\right|_{S(a)}=1$
(b)
IAndrew's ears are part of his body. $\left.\right|_{S(b)}=1$
Conclusion
(c)
$0<\mid$ Andrew's ears are big. $\left.\right|_{I(4)}<1$

This is a whole-part inference. Here the missing premise is a background assumption concerning the relation between the whole and the part:

(5) $0<$ IIf someone's head is big, then the parts of his head are big as well. $\left.\right|_{S}<1$

This statement is merely plausible to a certain extent. Accordingly:

(6) Premises
(a)
|Andrew's head is big. $\left.\right|_{S(a)}=1$
(b)
|Andrew's ears are part of his body. $\left.\right|_{S(b)}=1$
(c)
(d)
$\left[0<\right.$ IIf someone's head is big, then the parts of his head are big as well. $\left.\left.\right|_{S(c)}<1\right]$
$0<$ IAndrew's ears are big. $\left.\right|_{I(6)}<1$

It is easy to see that the plausibility value of the conclusion is very low. We will put latent background assumptions within square brackets in the inferences.

(c) The third type is the combination of the first two types: the inference includes at least one plausible statement among the premises and is enthymematic. For example, a classical inference of cognitive science is this:

(7) Premises

(a) $\quad 0<\mid$ Visual perception is organized in a modular way. $\left.\right|_{S(a)}<1$

(b) $\quad 0<$ IVisual perception is part of human cognition. $\left.\right|_{S(b)}<1$

Conclusion

(c) $\quad 0<\mid$ Human cognition is organized in a modular way. $\left.\right|_{I(7)}<1$

This is a part-whole inference. Both premises are merely plausible and the inference is enthymematic. The latent background assumption says:

(8) $0<$ IIf the part has a certain property, then the whole also has the same property. $\left.\right|_{S}<1$

\footnotetext{
${ }^{6}$ See e.g. Rapp (2010) for the history of this notion. Classical discussions of enthymematic plausible inferences are to be found in Polya $(1948,1954)$ and Rescher (1976). For an overview of the problems enthymematic inferences raise and the argumentation schemes in which they participate see Walton et al. (2008). See also Hitchcock $(1998,2017)$ on the criticism of the traditional treatment of enthymematic inferences and the current view.
} 
Like (5), this statement has a low plausibility value, too, because it cannot be supported by a direct source that is reliable in all known cases. There is no logical consequence relation between the premises and the conclusion in (7), but there is a semantic relation between them (namely, the part-whole relation). Relying on this inference as an indirect source one may assign only a relatively low plausibility value to the conclusion (7)(c).

\subsubsection{The p-Context}

The pieces of information which plausible inferences depend on constitute the p-context (Kertész and Rákosi 2012: 121-127). The p-context should be distinguished from the notion of context as used in pragmatics. In particular, the p-context contains methodological rules, the sources considered to be reliable and the plausible statements at one's disposal in compliance with the methodological rules and the sources. Since the first paragraph of Sect. 2.1 states that the p-model pertains to linguistic theory formation, it should be evident that the notion 'p-context' is much more specific than that of 'context' in pragmatics insofar as it is restricted to those methodological rules, sources and plausible statements which shape the plausibility value of statements as well as the structure and content of inferences in linguistic theories. As an illustrative example, consider the following statement:

(9) $0<$ In a linguistic theory contradictions between the data and the hypotheses may be temporarily tolerated, in the hope that the later development of the theory will resolve them, and in order to protect the theory's explanatory principles. $\left.\right|_{S}<1$

This is the so called 'principle of epistemological tolerance' that Chomsky advocates and attributes to Galileo. In generative linguistics, this methodological principle is part of the p-contexts of Government-Binding Theory and the Minimalist Program. $S$ is a complex direct source including Chomsky's and Galileo's authority. See Kertész (2012).

\subsubsection{P-Problems}

In the p-context p-problems may arise (Kertész and Rákosi 2012: 130-134). Basically, there are two kinds of p-problems. One of them arises if a statement is made plausible by a particular source while its negation is supported by another source. Such p-contexts are informationally overdetermined and the set of the plausible statements in the p-context is p-inconsistent. Second, the p-context may be informationally underdetermined, which means that it is $p$-incomplete in the sense that it includes at least one statement that is neither plausible nor implausible relative to the sources available. A p-context may be both informationally under- and overdetermined with respect to different statements. A solution of a p-problem is arrived at if the p-context at issue is no longer p-inconsistent or p-incomplete. However, it may be the case that a p-problem has more than one solution. The resolution of a p-problem is one of the solutions of the given p-problem which, according to the accepted criteria, is better than the other solutions put forward on the basis of the information at hand. For example (see also (26)):

(10) I"[I]ntellectual leadership is the sine qua non of scientific group formation. [...] In addition to intellectual leadership, either organizational leadership or the self-recruitment of a group of followers is necessary for the formation of a scientific group, according to the functionalist theory." $\left.\right|_{S}=0$ (Murray 1994: 479). 
The p-context of (10) is p-problematic. Namely, it is p-incomplete in that (10) is neither plausible nor implausible. Then, this p-problem would be solved if one could identify a source $S$ that is reliable enough to assign a positive plausibility value to the statement.

If a p-context includes a p-problem, then achieving a solution or the resolution of this p-problem may be needed. Achieving the solution or the resolution of a p-problem is $a$ heuristic aim (Kertész and Rákosi 2012: 127-128). Nevertheless, besides overcoming p-incompleteness and p-inconsistency (i.e. solving or resolving a p-problem in the sense introduced above), there may be other heuristic aims as well (for example, answering different kinds of questions, exemplifying a particular issue, providing additional information etc.).

\subsubsection{Plausible Argumentation}

In order to reach a particular heuristic aim raised in a p-context, a heuristic tool is needed. Such a heuristic tool is the process of plausible argumentation (Kertész and Rákosi 2012: 134-163). Plausible argumentation consists of a sequence of plausible inferences in the course of which alternative p-context versions are continuously retrospectively re-evaluated and compared. The retrospective re-evaluation of information proceeds in terms of cycles. The cycles may continuously change the perspective from which the information in the p-context is evaluated. Since, in this sense, the pieces of information in the p-context are viewed through the 'prisms' of later phases of the argumentation process, the cycles of the retrospective re-evaluation are prismatic. ${ }^{7}$ If the p-context was p-problematic in the above sense, then in the course of its cyclic, prismatic and retrospective re-evaluation, the plausible argumentation process will transform it into one in which its solution or resolution has been achieved. If the initial p-context includes a heuristic aim of a kind other than solving or resolving a p-problem, then the plausible argumentation process transforms the p-context into one in which this aim no longer arises.

\subsection{The Solution to (P2)}

In modern times, it was Hamblin's (1970) seminal work that subsumed the Aristotelian tradition under the definition which says that "a fallacious argument, as almost every account from Aristotle onwards tells us, is one that seems to be valid but is not so" (Hamblin 1970: 12; emphasis as in the original). ${ }^{8}$ Since Hamblin's criticism of this tradition new ideas have been put forward that also question the classical view and consider alternatives. ${ }^{9}$

At this point we may ask what account of fallacies the p-model can offer. The answer to this question follows immediately from the basic tenets of the p-model (see also Kertész and Rákosi 2009, 2012: 159-160):

\footnotetext{
7 See also Rescher (1976) on the cyclic and prismatic nature of what he calls 'plausible reasoning'.

8 The literature uses the term 'argument' in the sense of 'inference'. We will use 'inference' and distinguish it from 'argumentation' in the sense of the p-model as introduced in Sect. 2.1.

9 Although there are wide discussions within argumentation theory on the nature of fallacies, the two main trends are Walton's pragmatic approach (see among others Walton 1995, 1996, 1998, 2010, 2013a, b) and van Eeemeren's pragma-dialectical account (see e.g. van Eeemeren and Grootendorst 2004; van Eemeren et al. 2009). In the present paper we will not go into the comparison of the p-model's account of fallacies and these approaches.
} 
(D) Fallacies are particular stages in a plausible argumentation process which prevent a given cycle or the whole of the plausible argumentation process from fulfilling its heuristic aim.

(D) is a working definition and should be refined by later considerations.

The substantial difference between plausible and fallacious argumentation is that while plausible argumentation leads towards a particular heuristic aim (primarily, the solution or the resolution of a p-problem by comparing the plausibility values of alternative statements and thus deciding between them), fallacies block the argumentation process. In the sense of (D), fallacies are not isolated inferences but integral parts of the argumentation process consisting of one or more inferences that may affect many of its components. For example, fallacies may be related to the preference of a less plausible statement against a more plausible one, the insufficiency of the control of consistency, the involvement of irrelevant information, the disregarding of relevant sources or statements, the overestimation of the plausibility of the conclusion, the overestimation of the reliability of a source, etc.

A particular inference is not a fallacy per se. Rather, it depends on the peculiarities of the p-context whether a certain inference with a particular pattern works as a component of a fallacy in the sense of (D) or, rather, as an effective plausible inference. This can be decided only from case to case, with respect to the details of the plausible argumentation process.

At this point, the following hypothetical solution to (P2) suggests itself:

(SP2) The p-model may serve as the framework for analyzing fallacies in the historiography of generative linguistics

In the next section, we will presuppose (SP2) in order obtain a partial solution of (P1).

\section{On (P1): A Case Study}

\subsection{Introductory Remark}

In general, by using argumentum ad hominem, the speaker or writer attacks the character of the opponent instead of refuting his or her claims. There are many different ways this can be done. The literature distinguishes several main types of argumentum ad hominem, and a series of subtypes as well as borderline cases, which are subject to different evaluations.

We will exemplify three main types as they emerge in the historiography of generative linguistics. Let us begin with the 'abusive' ad hominem whose main feature is that it attacks a person's character directly. ${ }^{10}$

\subsection{Abusive Argumentum Ad Hominem and False Analogy}

In order to illustrate the abusive type, below we will quote a passage from an important state-of-the-art article by E.F. Konrad Koerner. Koerner (2006) is the concluding article in the handbook History of the Language Sciences. The article might significantly contribute to shaping the field, because the author, in his capacity as the chief editor of this handbook

${ }^{10}$ Walton (1996: 228 ff., 1998: 281) prefers the term 'direct' to 'abusive'. 
consisting of three bulky volumes, partly summarizes relevant insights concerning the history, the methodology and the current state of linguistic history writing, and partly puts forward his own preferences, admitting "a certain amount of personal bias" (Koerner 2006: 2802). Due to the relevance of the article for linguistic history writing in this respect, it is especially instructive to clarify whether the argumentation process it represents includes fallacies or not.

In Sect. 4 of the article, Koerner discusses four types of historiographical works, one of which he calls "celebratory or propagandistic histories of linguistics" (see Sect. 4.2 of his article). He refers to Berthold Delbrück's and Hermann Paul's books as representatives of this type, and then turns to Newmeyer's historiography of the first 20 years of generative linguistics ${ }^{11}$ :

(11) (a) “[...] Berthold Delbrück's (1842-1922) Einleitung served, together with Paul's Prinzipien of the same year, as the mouthpiece of a new generation of scholars eager to demonstrate that their achievements significantly surpassed previous attainments in the field, and that their theories should rightfully replace those taught by the preceding generation of linguists. The claim in favour of discontinuity is what characterizes this type of activity, and Delbrück's book is a prime example of this endeavor. [...]

(b) [...] in 1980, Frederick Newmeyer published a book which constitutes the best example to date of this pro domo, Whiggish type of history writing. It selects and reinterprets past linguistic research in an attempt to provide his view that linguistics was made a science only in 1955 (i.e. with the typescript compilation of The Logical Structure of Linguistic Theory, which appeared in print only in 1975!) or in 1957 (with the appearance of Syntactic Structures, by Noam Chomsky), and that previous work was totally inadequate, barring a few minor incidental insights fore shadowing the 'revolution' in the field (cf. Koerner 1983, for critical assessment of this kind of activity). Coincidentally, Newmeyer's Linguistics in America (1980), appeared exactly 100 years after Delbrück's Einleitung, but parallels between their authors are striking indeed: Both were less than 40 when they wrote their books: both were primarily interested in syntax, not phonology, and neither had done his doctorate at the respective centers of schools whose success story they depicted. (Delbrück did both his doctorate and habilitation in 1863 and 1867, respectively, under August Friedrich Pott in Halle, and not under Georg Curtius in Leipzig; Newmeyer took his doctorate in 1969 under the direction of Robert B. Lees at the University of Illinois, not MIT.)" (Koerner 2006: 2812) ${ }^{12}$

The example in (11) represents a relatively complex stage in a plausible argumentation process in the sense of the p-model. Among others, it includes inferences which, with respect to their status within the plausible argumentation process might, but need not, turn out to be fallacious: a potential ad hominem argumentation and analogical argumentation. The question is, whether the p-model analyzes (11) as a fallacious stage or as a plausible stage in Koerner's argumentation process.

Let us consider first the possibility of ad hominem argumentation. According to Walton et al. (2008: 142) ad hominem inferences have the following general argumentation scheme: "Character Attack Premise: $a$ is a person of bad character. Conclusion: $a$ 's argument $\alpha$ should not be accepted."

From the point of view of the p-model as well as (11), three remarks present themselves with respect to this general structure. First, it looks like an enthymematic plausible

\footnotetext{
11 We will divide the quotations into smaller units in order to make it easier to refer to parts of the quotation to be analyzed. The units do not necessarily correspond to paragraphs in the original text.

12 Koerner did not quote the title of Newmeyer's book precisely; the title of the book is Linguistic Theory in America.
} 
inference conforming to type (c) as mentioned in Sect. 2.1.3. However, whether it is indeed a plausible inference depends on the plausibility of the premises, the semantic relations and the latent background assumptions. Second, in the Character Attack Premise the expression 'bad character' must not be interpreted literally. What matters here is that the person attacked is attributed a property which in the particular p-context is evaluated negatively in a sense determined by the p-context. Third, as (D) suggests, the p-model does not restrict fallacies to single inferences, but treats them as stages in the plausible argumentation process. A stage may consist of one inference, but, depending on the particular properties of the p-context, it may also include more than one inference. Accordingly, among others we may obtain the following two inferences as a partial reconstruction of the argumentation structure of $(11)(b)^{13}$ :

(12) Premises

(a) [IIf a historiographer of generative linguistics has not taken his/her doctorate at MIT and this is a negative property, then he/she is not a competent expert in his/her field of research. $\left.\right|_{S(a)}=$ ?]

(b) [INot having received one's $\mathrm{PhD}$ from MIT is a negative property of a historiographer of generative linguistics. $\left.\right|_{S(b)}=$ ?]

(c) Frederick Newmeyer is a historiographer of generative linguistics who did not take his doctorate at MIT. $._{S(c)}=1$

Conclusion

(d) $\quad 0<\mid$ Frederick Newmeyer is not a competent expert in his field of research. $\left.\right|_{(I 2)}=$ ?

(13) Premises

(a) $\quad[0<$ IIf a historiographer of generative linguistics is not a competent expert in his/her field of research, then his/her statements on the history of generative linguistics should not be accepted. $\left.._{S(a)}<1\right]$

(b) $\quad$ Frederick Newmeyer is not a competent expert in his field of research. $\left.\right|_{S(12)(d)}=$ ?

Conclusion

(c) IFrederick Newmeyer's statements on the history of generative linguistics should not be accepted. $I_{I(13)}=$ ?

The question marks indicate the substantial uncertainty of the statements which (12) and (13) consist of. If the premises are plausible, then the structure of (12) and (13) corresponds to the pattern of plausible modus ponens. Nevertheless, the structure itself does not require that the inference must have an ad hominem effect, nor that it is a plausible inference. Against the background of the p-model, depending on the reliability of the source of the plausibility value of the statements, the semantic relations they involve, and the latent background assumptions, the inference leads to a conclusion which may be plausible to a certain extent or implausible, or of neutral plausibility. Let us have a look at the factors whose interplay may decide this issue.

(12)(c) is a true statement. The crucial statements among the premises are the latent background assumptions (12)(a) and (b). The plausibility value of (12)(a) and (b) depends on the reliability of their sources (see Sect. 2.1.2 for the notion of 'source' in the sense

\footnotetext{
${ }^{13}$ Latent background assumptions are put within square brackets. In the conclusions of the inferences $I$ stands for 'indirect source'.
} 
used here), which include Konrad Koerner's judgment. Obviously, if the reader does not regard Konrad Koerner as a reliable source in this case, then it is questionable at the outset whether (12)(a) and (b) can be assigned a positive plausibility value. $S(a)$ and $S(b)$ may include another source as well. Namely, in the p-context of Koerner's argumentation process, a second source within $S(a)$ and $S(b)$ seems to be the assumption that there is a hierarchy of American universities (see also Murray 1994). In this hierarchy, generative linguistics dissertations taken at MIT assume the highest position. If it is this assumption that is one of the sources of the plausibility value of (12)(a) and (b), then this plausibility value is also high; if this source is held to be unreliable, then it cannot support the plausibility of (12)(a) and (b), which will be therefore of neutral plausibility. ${ }^{14}$

Between statements in a plausible inference there may be semantic relations which can be interpreted in different ways and which influence the plausibility value of the conclusion: for example, whole-part relation, part-whole relation, relevance etc. Besides the reliability of the sources, the plausibility value of (12)(a) also depends on a semantic relation between the two clauses of this latent background assumption. Namely, the argumentation theoretical literature treats argumentum ad hominem as a fallacy of relevance (e.g. Walton 1998: $268 \mathrm{ff}$. etc.). If one believes that the university at which one has taken his/her $\mathrm{PhD}$ is not relevant for his or her being or not being an expert in his/her field of research, then (12) (a) will not be plausible and as a consequence, (12)(d), (13)(b) and (13)(c) will be of neutral plausibility as well. The crucial question is, of course, what one means by 'relevance'. This is a complicated issue whose discussion would go beyond the limits of this paper (see e.g. Walton 2013a). Nevertheless, the p-model suggests that what counts as relevant is basically p-context dependent. In the p-context of (11), this means that relevance should be explicated as a cause-effect relation: that is, whether the university of one's $\mathrm{PhD}$ is or is not the cause of this person's being or not being an expert in his/her field of research.

Moreover, the very phase of the plausible argumentation process represented in (11) is more complicated, among other things, because there is another potentially fallacious inference which in the given p-context may influence the plausibility value of the conclusion of (13). Namely, the parallels drawn between Delbrück and Newmeyer give rise to an analogical inference. This is a case which Waller (2001: 199) characterizes in this way: "When disputes turn from ad hominem attacks and strawman distortions toward serious argument, there is no better means of convincing listeners and settling debates than by effective use of analogies."

Analogical inferences are typical inferences which may be fallacious or, on the contrary, effective tools of problem solving (Walton et al. 2008: $48 \mathrm{ff}$.). Thereby, the main question is what kind of relation there is between the properties in the premises and the conclusion. The answer is that in analogical inferences there is also a relation of relevance on which the plausibility value of the conclusion will depend. ${ }^{15}$

\footnotetext{
14 A reviewer remarked that (12)(a) may also be interpreted as a claim about whether the history of a tradition is better written by insiders to it or not. This is one of the factors that may make the comparison with Delbrück relevant.

15 Copy and Burgess-Jackson (1992: 199) define this relation with respect to relevance in a similar way to how we characterized it with respect to (12):

"[...] an analogy is relevant to establishing the presence of a given attribute provided it is drawn with respect to other circumstances affecting it. One attribute or circumstance is relevant to another, for purposes of analogical argument, if the first affects the second, that is, if it has a causal or determining effect on the other."
} 
Another important consideration is that, since there are several types of analogical inference (see e.g. Waller 2001; Guarini 2004; Walton et al. 2008), we must answer the question of which particular type of analogical inference-in our case, that in (11)(b) - we are dealing with. In our case it is of the inductive kind. Waller (2001: 202) identifies the structure of inductive analogical inferences as follows:

(14) Premises
(a)
$D$ has characteristics $e, f, g$, and $h$.
(b)
$E$ also has characteristics $e, f, g$, and $h$.
(c)
$D$ also has characteristic $k$.
(d) Having characteristics $e, f$, $g$, and $h$ is relevant to having characteristic $k$.
Conclusion
(e) $\quad E$ will also have characteristic $k$.

Based on this pattern, the analogical inference in (11)(b), as a component of a particular stage in Koerner's argumentation process, can be reconstructed like this:

(15) Premises

(a) IDelbrück was less than 40 when he wrote his book, he was primarily interested in syntax, not phonology, and he had not done his doctorate at the center of the school whose success story he depicted. $I_{S(a)}=1$

(b) INewmeyer was also less than 40 when he wrote his book, he was also primarily interested in syntax, not phonology, and he also had not done his doctorate at the center of the school whose success story he depicted. $\left.\right|_{S(b)}=1$

(c) $\quad 0<$ IDelbrück's book is the prime example of pro domo or Whiggish history writing. $\left.\right|_{S(c)}=$ ?

(d) [lHaving the characteristics of being less than 40 when writing one's book(s), being primarily interested in syntax, not phonology, and doing one's doctorate at the respective center of the school whose success story one depicted is relevant to having written a book that is the prime example of pro domo or Whiggish history writing.| $\left.\right|_{S(d)}=$ ?]

Conclusion

(e) INewmeyer's book is also a prime example of pro domo or Whiggish history writing. $\left.\right|_{I(15)}=$ ?

Trivially, the sources $S(a)$ and $S(b)$ are biographical data. $S(c)$ is Koerner's judgment. The crucial question is whether in the p-context of $(11)(b)$, the semantic relation between the clauses in (15)(d) is evaluated as relevant or not. If the criterion of relevance is not satisfied, that is, the properties enumerated in (15)(a) and (b) are causally not related to a book's being an instance of Whiggish history writing, ${ }^{16}$ then neither (15)(d) nor (15)(e) can be plausible.

There seems to be a close interaction between (13) and (15) during the cyclic and prismatic argumentation process. (13)(c) and (15)(e) cyclically (but not circularly) feed back to each other and re-evaluate each other's plausibility within the given p-context. Thus, (13) (c) may serve as an additional direct source of the plausibility value of (15)(e), and (15)(e) may be an additional direct source of the plausibility value of (13)(c). This re-evaluation is

\footnotetext{
16 According to the historian Henry Butterfield, 'Whig history' is a "system of immediate reference to the present day, [in] which historical personages can easily be classed into the men who furthered progress and the men who tried to hinder it" (Butterfield 1931: 11).
} 
also prismatic because the perspective from which it is carried out changes: (13)(c) is reevaluated from the perspective of (15)(e), and vice versa. In summary:

(16) IFrederick Newmeyer's statements on the history of generative linguistics should not be accepted $_{I(13),(15)(e)}=$ ?

INewmeyer's book is a prime example of pro domo or Whiggish history writing. $\left.\right|_{(13)(c), I(15)}=$ ?

We must remember that according to the p-model, plausible argumentation is a heuristic process, which, starting from a problematic p-context, moves toward a final p-context including a solution or the resolution of the initial p-problem. So, in order to decide whether the argumentation stage in (11)(b) is fallacious or not, we have to examine the role (12), (13) and (15) play in the argumentation process from this point of view. To do so, we have to know what the p-problem is and toward what solution Koerner's argumentation proceeds.

Koerner does not raise the p-problem of Sect. 4 of his paper explicitly. However, since he discusses and evaluates four types of linguistic history writing, it is easy to identify his initial p-problem in this section. Clearly, the p-context is p-problematic insofar as it is p-incomplete (for the notion of p-incompleteness see Sect. 2.1.5), because at this stage of the argumentation process there are four claims none of which can be assigned a plausibility value:

(18) (a) IHistories of linguistics have the function of summing up previous findings that have been reached. $I_{S}=0^{17}$

(b) Histories of linguistics have the function of celebrating or propagating achievements that replace findings of the previous generation. $\left.\right|_{S}=0^{18}$

(c) IHistories of linguistics have the function to present a detached view of the development of linguistics ("Problemgeschichte"). $\left.\right|_{S}=0^{19}$

(d) IHistories of linguistics have "a function comparable to that of the history of science for the natural scientist" (Koerner 2006: 2814). $\left.\right|_{S}=0^{20}$

The p-problem would be solved if at least one of the rival statements in (18) could be assigned a positive plausibility value and, as a result of this, the remaining ones could be discarded. The solution Koerner suggests is the re-evaluation of the p-context so that the statement in (18)(d), namely, his own approach gets a high plausibility value. Thereby, he

\footnotetext{
17 Summing-up histories "viewed the evolution of the field as growing in an essentially unilinear fashion" (Koerner 2006: 2811). The source $S$ is the literature cited by Koerner (e.g. Benfey 1869).

18 Works belonging to this type are "the mouthpiece of a new generation of scholars eager to demonstrate that their achievements significantly surpassed previous attainments in the field, and that their theories should rightfully replace those taught by the preceding generation of linguists" (Koerner 2006: 2812). The source $S$ includes among others Delbrück (1880) and Newmeyer (1980).

19 The source $S$ includes e.g. Arens (1969). Works belonging to this type indicate that "we all have built [...] on the findings of previous generations of linguists, and that we owe much more to these scholars than we might ever become fully aware of" (Koerner 2006: 2813).

20 The source $S$ consists primarily of Koerner's own works. Such works focus on "the presentation of our linguistic past as an integral part of the discipline itself and, at the same time, as an activity founded on well-defined principles which can rival, in terms of soundness of method and rigour of application, those of linguistics itself." (Koerner 2006: 2814). In addition, it is worth remarking that this claim may have a normative aspect in that Koerner 'demands' that the historiography of linguistics should assume the function mentioned.
} 
distances himself, among others, from all the other types of linguistic history writing, in particular, from what he calls pro domo, or Whiggish or partisan historiography. Thus, the partial solution to this p-problem which Koerner seems to suggest in the final p-context of the plausible argumentation process is the re-evaluation of the p-context by assigning a positive plausibility value to (18)(d) while leaving the rival statements unchanged. Accordingly, the p-context is enriched by the inclusion of the following plausible statement:

(19) $0<$ IHistories of linguistics have "a function comparable to that of the history of science for the natural scientist". $I_{I(12), I(13), I(15)}<1$

However, (12), (13) and (15) cannot exert their heuristic function, because they do not move the argumentation process toward the solution in (19) of the p-problem in (18). The first reason why this is so is that, as we have seen above, whether an inference is plausible or fallacious does not depend only on its structure, but it also depends on the semantic relations between the statements in the inference. If the p-context triggers evaluations of these semantic relations which contribute to the neutral plausibility of a given premise, then the conclusion will be of neutral plausibility, too. The semantic relation between the clauses in (12)(a) and (15)(d) is irrelevant rather than relevant. Therefore, (12)(d), (13)(c) and (15)(e) are of neutral plausibility.

The second factor is that (13)(c) and (15)(e) are conclusions of enthymematic inferences. The latent background assumptions are not identifiable with certainty, which may also contribute to the neutral plausibility of the conclusion. ${ }^{21}$

Third, certain sources, as we have mentioned, may be unreliable. If a source is unreliable, then it cannot make the statement at issue plausible. Therefore, such statements cannot be assigned a plausibility value. This applies to (12)(a) and (b) as well, and accordingly, the conclusion of (12) will also have no plausibility value.

So, (12)(d), (13)(c) and (15)(e) turn out to be of neutral plausibility. Accordingly, all the statements in (12), (13) and (15) whose unknown plausibility value was symbolized by a question mark (as well as (16) and (17)) should be modified so that they have the structure (1)(b).

An inference with a conclusion of neutral plausibility may trigger the fallaciousness of an argumentation stage. That (12), (13) and (15) constitute a fallacious stage in the plausible argumentation process is due to the circumstance that because their conclusions are of neutral plausibility, they cannot exert their heuristic function. They do not work as stages which lead to the solution of the p-problem at issue. Namely, in a plausible argumentation process, which consists of sequences of plausible inferences, normally the conclusion of a particular plausible inference may be used as the premise of a further plausible inference in a later stage. Thus, such a conclusion of one plausible inference which is re-used as a premise in the next, eventually contributes to the solution or the resolution of the p-problem, at least indirectly, as one piece in the chain of plausible inferences. Since (12)(d), (13) (c) and (15)(e) turn out to be of neutral plausibility, as premises of later inferences they cannot further the solution of the p-problem in (18) which Koerner expects and which we reconstructed in (19). Since they are not plausible, they cannot make (18)(d) plausible, that

\footnotetext{
21 The identification of the latent background assumptions is an intricate matter:

"One problem with enthymemes is that reasonable people can have differences of opinion on what the implicit assumptions are supposed to be. Filling in the missing parts of an enthymeme may depend on interpreting the natural language text in which the argument was put forward [...]" (Walton et al. 2008: 189).
} 
is, (19) cannot be inferred. Since they cannot contribute to inferring (19), they even block the argumentation process and constitute a hindrance that does not allow to arrive at the solution of the p-problem at issue. In contrast to (19), in an inference in which (13)(c) and (15)(d) work as premises, the statement in (20)(d) as a conclusion will also be of neutral plausibility:

(20) Premises $^{22}$

(a) IFrederick Newmeyer's statements on the history of generative linguistics should not be accepted. $I_{I(13)}=0$

(b) INewmeyer's book is a prime example of pro domo or Whiggish history writing. $._{I(15)}=0$

(c) IIf Frederick Newmeyer's statements on the history of generative linguistics should not be accepted and Newmeyer's book is also a prime example of pro domo or Whiggish history writing, then histories of linguistics have "a function comparable to that of the history of science for the natural scientist." $\left.\right|_{S(c)}=0$

Conclusion

(d)

IHistories of linguistics have "a function comparable to that of the history of science for the natural scientist." $\left.\right|_{I(20)}=0$

Here the sources of the plausibility values of (20)(a) and (b) are (13) and (15), respectively, which cannot make them plausible. The source of the plausibility value of (20)(c) is Koerner's judgment. Irrespective of whether the source of the plausibility value of (20) (c) is considered to be reliable or not, and, accordingly, the statement plausible or not, the conclusion, i.e. the solution to the initial p-problem in (18), will not be plausible (because (20)(a) and (b) are not plausible, but of neutral plausibility).

In sum, the above characterization of Koerner's argumentation process seems to satisfy our working definition of 'fallacy' in (D): consequently, the argumentation stage represented in (11) and consisting of the inferences (12), (13), (15) and (20) is fallacious. However, it is worth remarking that we analyzed only one stage of Koerner's argumentation process and not the whole of it, so we cannot exclude at the outset that there may be further stages which, in the long run, increase the plausibility value of (19).

\subsection{Circumstantial Argumentum Ad Hominem}

In the circumstantial ad hominem argument, it is claimed that what a certain person advocates contradicts what this person seems to assume in his or her personal circumstances.

The example we have chosen to illustrate the circumstantial ad hominem argument is (21) and (22). First, Murray (1994: 445) quotes Newmeyer who characterized GovernmentBinding Theory (abbreviated as $G B$; later called 'the Theory of Principles and Parameters'-abbreviated as $P P$ ) as follows:

(21) (a) "And the special lure is that anyone can do it $[\ldots]$

(b) Vast arrays of new facts keep being discovered in studies carried out in the GB research paradigm on countless languages [...] GB is overwhelmingly more productive in bringing new facts into the literature than any other framework." Newmeyer (1980: 226)

$22(20)(d)$ may have a normative aspect. 
Then, referring to this quotation, Murray maintains ${ }^{23}$ :

(22) (a) "The longrunning MIT ethos of imperviousness to criticism and contempt for empirical data continue to encourage ceaseless revision of principles announced in inhouse communications not subject to review by outsiders (even the previous cohort of MIT students)

(b) Cohort after cohort of MIT students emulates Chomsky's contemptuous rhetoric dismissing those who have not accepted his latest revelations. The contents change, the style remains the same. Constant purges, persistent rhetoric about a sacred 'revolution' accompanied by persistent misgovernment as judged by any external standards recalled Stalin [...]. The 'Cultural Revolution' of Mao Zedong [...] is an even better political analog for the Chomskian regime: the aging dictator questions the zeal and loyalty of his former followers, and encourages the ferocity of the young, who gladly challenge 'traditions' of all ages

(c) 'Anyone can do it.' Although some have hailed GB/PP as a new consensus, the influence of Chomsky's work, as measured by citations, has fallen during the diffusion of the newest orthodoxy." (Murray 1994: 445)

The potential fallacy in the argumentation stage that (22) represents can be decomposed into three inferences. The first is an analogical inference that follows the pattern in (14):

\section{(23) Premises}

(a)

(d)

Conclusion
$0<$ The characteristics of Stalin's and Mao Zedong's regimes are that there are constant purges, persistent rhetoric about a sacred 'revolution' accompanied by persistent misgovernment as judged by any external standards and that the aging dictator questions the zeal and loyalty of his former followers, and encourages the ferocity of the young, who gladly challenge 'traditions' of all ages. $\left.\right|_{S(a)}<1$

IThe characteristics of Chomsky's regime are also that there are constant purges, persistent rhetoric about a sacred 'revolution' accompanied by persistent misgovernment as judged by any external standards and that the aging dictator questions the zeal and loyalty of his former followers, and encourages the ferocity of the young, who gladly challenge 'traditions' of all ages. $\left.\right|_{S(b)}=$ ?

$\left[0<\mid\right.$ Stalin's and Mao Zedong's regimes are unacceptable. $\left.\left.\right|_{S(c)}<1\right]$

[ $\mid$ Being characterized by constant purges, persistent rhetoric about a sacred 'revolution' accompanied by persistent misgovernment as judged by any external standards and that the aging dictator questions the zeal and loyalty of his former followers, and encourages the ferocity of the young, who gladly challenge 'traditions' of all ages is relevant to a regime's being unacceptable. $\left.\right|_{S(d)}=$ ?]

(e)

IChomsky's regime is unacceptable. $\left.\right|_{(23)}=$ ?

The direct sources $(S)(a)$ and $(S)(b)$ consist of historical documents which may or may not support the plausibility of the statements. Thereby, the reliability of the historical documents supporting the plausibility value of (23)(a) as its direct source are certainly higher than the direct source of the plausibility value of (23)(b). $(S)(c)$ may be Murray's judgment. Since we have already discussed this type of analogical inference with respect to (15) in Sect. 3.2, we will not go into the details of (23) at this point. We merely remark that the crucial components are (23)(b) and (d). The plausibility of (23)(b) depends on whether this characterization indeed applies to the way Chomsky organizes his environment and to

\footnotetext{
${ }^{23}$ Please notice the highly pejorative character of the word 'regime' in (22)(b). It is an important question in what way and to what extent the p-model can capture rhetorical effects. See on this Kertész (2017: 180-181).
} 
what extent the source mentioned is assumed to be reliable. It may even be neutral, because proponents of generative linguistics may question the authenticity, and thus, the reliability of the documents Murray has in mind. The plausibility of (23)(d) depends on the reliability of the documents Murray has in mind as well as how the relevance relation is judged.

The second inference is the subtype called 'group circumstantial ad hominem' in Walton et al. (2008: 151). See also the quotation in $(21)^{24}$ :

(24) Premises

(a)

$0<$ IWithin the GB framework it is possible to discover a great number of new facts about a great number of languages. $\left.\right|_{S(a)}<1$

(b) $\quad 0<$ Everybody in the group of generative linguists should be committed to this claim. $\left.\right|_{S(b)}<1$

(c) [IChomsky belongs to the group mentioned. $\left.\left.\right|_{S(c)}=1\right]$

(d) $\quad[0<$ IChomsky has carried out actions that imply that Chomsky is personally committed to the opposite of the claim in premise (a) in that he is impervious to criticism and shows contempt for empirical data which encourages ceaseless revision of principles announced in inhouse communications not subject to review by outsiders while several generations of his followers dismiss those who have not accepted his latest revelations. $\left.\left.\right|_{S(d)}<1\right]$

(e) [IIf (a), (b), (c) and (d) are the case, then Chomsky's actions are unacceptable. $\left.\right|_{S(e)}=$ ?]

Conclusion

(f)

IChomsky's actions are unacceptable| $\left.\right|_{I(24)}=$ ?

In (24), the direct sources $S(a)$ and $S(b)$ are Newmeyer's (1980: 226) claim we have quoted in (21). The direct source $S(c)$ is the knowledge that Chomsky is the author of Lectures on Government and Binding. For $S(d)$, see (22)(a).

The third inference uses the conclusions of (23) and (24) as premises:

(25) Premises

(a) [IChomsky's regime is unacceptable. $\left.\right|_{I(23)}=$ ?]

(b) $\quad\left[\mid\right.$ Chomsky's actions are unacceptable| $\left.\right|_{I(24)}=$ ?]

(c) [IIf Chomsky's regime and actions are unacceptable, then Government-Binding Theory should not be accepted. $\left.\left.\right|_{S(22)(b)}=0\right]$

Conclusion

(d) IGovernment-Binding Theory should not be accepted. $\left.\right|_{I(25)}=0$

The heart of the circumstantial ad hominem argumentation is the inference in (25). Irrespective of whether (25)(a) and (b) are plausible or not, the crucial premise is (25)(c) for evaluating the whole of the argumentation stage as ad hominem. Namely, (25)(c) is again based on the relation of relevance (Walton et al. 2008: 151). If we interpret the relevance relation in (25)(c) in Walton et al.'s sense, then it is not the case that Chomsky's actions and regime being unacceptable is "good reason" for concluding that Government-Binding Theory should not be accepted, and therefore (25)(c) cannot be made plausible.

\footnotetext{
${ }^{24}$ Walton et al. (2008: 151) define one argumentation scheme of this type. Here we decomposed the argumentation scheme Walton et al. suggest into (24) and (25), and of course, interpret the premises as plausible statements.
} 
With respect to (23)-(25), we see again that it is not a single inference that might be fallacious, but a sequence of inferences constituting a particular stage within a plausible argumentation process.

(23)-(25) jeopardize any possibility of reaching the solution of Murray's p-problem. Namely, Murray (1994) develops a version of Griffith and Mullins' (1972) sociological approach to the formation of scientific groups and aims to test this by carrying out case studies on-among other things - the history of generative linguistics. He hypothesized (26), which made the initial p-context p-incomplete and thus p-problematic, because it could not be assigned a plausibility value $\mathrm{e}^{25}$ :

(26) I“[I]ntellectual leadership is the sine qua non of scientific group formation. [...] In addition to intellectual leadership, either organizational leadership or the self-recruitment of a group of followers is necessary for the formation of a scientific group, according to the functionalist theory." $\left.\right|_{S}=0$ (Murray 1994: 479).

Murray (1994: 480) claims to have been able to make (26) plausible: "No reason to modify the functionalist model [...]". Yet (23)-(25) constitute an obstacle to reaching such a solution and thus count as a fallacious argumentation stage in which circumstantial $a d$ hominem and false analogy interact. Instead of continuing the analysis in a similar way as we did in Sect. 3.3, we refer to John E. Joseph's review article which is a convincing and simple illustration of the fallaciousness of this argumentation stage (but, of course not of all argumentation stages in Murray's book). After having quoted the passage in (22), Joseph concludes that "[...] for a historian to equate a scholar whose tactics he dislikes with the great mass murderers of the century hardly inspires confidence in his detachment and objectivity" (Joseph 1995: 387; emphasis added).

\subsection{Bias Argumentum Ad Hominem}

A third type of ad hominem argumentation is what the literature calls 'bias ad hominem' (e.g. Walton 1996: 220 ff., 1998: 11 ff., 228 ff., 288 ff.). In this type, one person accuses another of not being impartial because he or she is interested in supporting one of the competing views. We illustrate this type by a quotation from Robin Lakoff's memoir in which she told the story of generative semantics, as she experienced and evaluated it. Lakoff (1989: 940) characterized Newmeyer's (1980) account of the same period as follows:

(a) "Newmeyer's work has been valuable to me in clarifying other perspectives and encouraging me to put some years of thoughts on paper. Newmeyer certainly is to be admired for working through a formidable amount of complex, contradictory, and often ill-expressed prose in an attempt to make sense of 15 years of theoretical developments in linguistics.

(b) $[\ldots]$ I feel that his work suffers from flaws which detract critically from its utility and belie its author's claim to be presenting a generally dispassionate history. Newmeyer's bias is the most dangerous kind-inexplicit, perhaps not fully recognized even by the author. No one who lived through the period as a participant in the 'linguistics wars' can claim the status of disinterested observer. By his appearance of doing so, Newmeyer misleads the reader and distorts the facts. I believe that, when a historian is in a position to be biased, it is his or her responsibility to discover the form and extent of that subjectivity, and make it clear to the audience" (Lakoff 1989: 940; emphasis added).

${ }^{25}$ See also Kertész (2017) on the evaluation of Murray's hypotheses. 
We focus on (27)(b) and will return to (27)(a) later. The stage of Lakoff's (1989) plausible argumentation process as represented in (27)(b) can be decomposed into the plausible inferences in (28) and (29).

(28) Premises

(a) INewmeyer, the author of Linguistic Theory in America, is biased. $\left.\right|_{S(a)}=$ ?

(b) [IIf a person is biased, then he or she should not be given as much credibility as he or she would have without the bias. $\left.\left.\right|_{S(b)}<1\right]$

Conclusion

(c) INewmeyer should not be given as much credibility as he would have without the bias. $I_{(28)}=$ ?

The p-context of Lakoff's argumentation process includes, among others, the latent background assumption (29)(a) which is important as a premise in (29) (see Kertész 2017: 107):

(29) Premises

(a) $\quad[0<$ IIf Newmeyer pretends his evaluations are objective, while they represent Chomsky's interests, then Newmeyer should not be given as much credibility as he would have without the bias. $]\left.\right|_{S(a)}<1$

(b) INewmeyer should not be given as much credibility as he would have without the bias. $\left.\right|_{(b)}=$ ?

Conclusion

(c) $\quad 0<\mid$ Newmeyer pretends his evaluations are objective, while they represent Chomsky's interests. $I_{I(29)}<1$

Basically, (28) conforms to the pattern of bias ad hominem discussed in the literature (see, e.g. the argumentation scheme in Walton 1995: 153, Walton et al. 2008: 338-339). ${ }^{26}(29)$ is more interesting. Its structure is this:

(30) Premises
(a) If $p$, then $q$
(b) $q$
Conclusion
(c) $\quad p$

With respect to (30), (29) can be evaluated in three different ways: as a formal fallacy, as an informal fallacy or as a plausible inference. Let us see, why.

First of all, we must make a brief digression in order to clarify the distinction between two kinds of fallacies. Formal fallacies arise from an error in the logical form of an inference and do not depend on the content of the premises; examples of formal fallacies are 'affirming the consequent', 'denying the antecedent' etc. Informal fallacies depend on the content of an inference; for example, argumentum ad hominem, argumentum ad verecundiam, false analogy etc. It is informal fallacies that are currently the center of attention in argumentation theoretical research.

${ }^{26}$ On argumentation schemes see also Macagno and Walton (2018) as well as Walton (2006). 
On the one hand, from a logical point of view, the structure in (30) is an invalid inference pattern and it is (in the sense of the classical framework as analyzed in Hamblin 1970) one of the paradigmatic cases of formal fallacies called 'affirming the consequent'.

On the other hand, the pattern in (30) plays a central role in argumentation. Peirce considered this pattern to be one of the basic tools of scientific inquiry, called 'abduction'. Polya, one of the first scholars to systematically investigate the nature of plausible inferences, characterized (30) as "the simplest and most widespread pattern of plausible reasoning" (Polya 1948: 222), and handled it as the paradigmatic example of plausible inference. He analyzed a great number of examples showing that, although logically not valid, this pattern is a fruitful heuristic tool both in mathematics and in everyday reasoning. Lukasiewicz (1970 [1912]: 7) uses the term 'reduction' in order to refer to inferences which go in the 'opposite direction' to deduction: "Reasoning which starts from reasons and looks for consequences is called deduction; that which starts from consequences and looks for reasons is called reduction". The p-model adopts the term 'reduction'. ${ }^{27}$

As regards (29), it is important to realize that the point of departure for its evaluation is not logic-which would deem it fallacious for affirming the consequent at the outset-but reduction, a type of plausible inference whose acceptability depends not only on its form but on the semantic content of the plausible statements in the premises and the reliability of the sources as well. So, (29) cannot be a formal fallacy, but it may be assessed either as (part of) an informal fallacy or as a plausible inference. In order to see which is the case, we have to clarify what Lakoff's initial p-problem is and toward which solution her argumentation proceeds. After referring briefly to historiographical accounts of the generative semantics movement by Newmeyer and some members of a younger generation, Lakoff's starting $\mathrm{p}$-context is p-problematic in the sense that it is p-incomplete:

(31) IThe intellectual differences between interpretive and generative semantics triggered by Aspects originate from the different evaluation of the scientific method, and the differences between two kinds of personality involved in the debate. $\left.\right|_{S}=0$

The final p-context is expected to make (31) plausible (see also Kertész 2017: 64 ff.) which would amount to a solution of the p-problem.

The crucial factor is the plausibility value of (29)(b), which is identical to (28)(c), while the latter depends on the plausibility value of (28)(a). The plausibility value of (28)(a) is determined by the reliability of its source, which is Lakoff's (1989) paper. However, this paper does not include an analysis of Newmeyer's views nor a comparison of these views with Lakoff's approach; rather, it is restricted to a presentation of Lakoff's experiences. Therefore, this source cannot support the plausibility of (28)(a), which is neither plausible nor implausible. Consequently, (28)(c), (29)(b) and (29)(c) will be of neutral plausibility as well. Thus, in the long run, the argumentation stage culminating in (29)(c) will prevent the plausible argumentation process from, or at least hinder it in, reaching its heuristic aim,

\footnotetext{
27 It is worth remarking that in reduction, at least one of the premises in the pattern in (32) is merely plausible instead of being true with certainty and, as a consequence, the same is true of the conclusion, as well. If one takes (30) as a deductive inference consisting of true premises, then it is the formal fallacy of affirming the consequent. If, however, at least one of the premises and, consequently, the conclusion are merely plausible instead of being true with certainty, then it is a reduction which, depending on the p-context of the argumentation process, may, but need not, be an effective tool of problem solving.

Another remark is that the term 'reduction' must not be confused with 'theoretical reduction' as an intertheoretical relation used in the philosophy of science (as well as, for example, in Chomsky 2000).
} 
i.e. assigning a positive plausibility value to (31). Thus, it deems the argumentation stage in (27) a fallacy.

Now let us compare (27)(a) with (32). (32) is an example of 'poisoning the well', a subtype of bias ad hominem argumentation:

(32) " $[\ldots]$ I am surprised to find it [the University of Chicago Press] serving as an organ for the cynical misrepresentation of the past which is characteristic of Stalinist history, whether of political or of academic power grabs self-legitimated as 'revolutions'. There is hardly a page in it that doesn't exemplify the distortions of a perspective that takes Chomsky's pronouncements as the telos of human thought. Having already offered a warning to the customer that the book is wildly biased and unsuitable as a textbook either for history or linguistics, I will point to some of the more egregious misrepresentations of the history of linguistics in the book. There is hardly a page in it that doesn't exemplify the distortions of a perspective that takes Chomsky's pronouncements as the telos of human thought."

(Murray 1989: 156-157; emphasis added)

In the poisoning the well subtype, the attacked person is accused of being so dishonest that nothing he or she says can be assumed to be reliable (Walton 1996: 230, 1998: 14 ff., 230 ff.). In (32), after charging the Chicago University Press with having published Newmeyer's (1986) book, Murray attacks Newmeyer in a typical 'poisoning the well' way. The reconstruction of the argumentation structure of (32) would be analogous to (28) and (29) with one significant difference regarding the evaluation of the premises. Namely, as (27)(a) witnesses, Lakoff does not claim that everything Newmeyer claims is wrong; her evaluation of Newmeyer's stance is quite differentiated. In contrast to (27)(a), (32) makes the claim about another book by him that "there is hardly a page in it that doesn't exemplify the distortions of a perspective that takes Chomsky's pronouncements as the telos of human thought". Therefore, in the given p-context such an exaggeration-which cannot be supported by the source in question, i.e. Murray's paper-must not be evaluated as plausible:

(33) Premises

(a) In all his writings, Newmeyer, the author of The Politics of Linguistics, is biased. $\left.\right|_{S(a)}=0$

(b) $\quad[0<$ IIf a person is so biased, then he or she should not be given as much credibility as he or she would have without the bias. $\left.\left.\right|_{S(b)}<1\right]$

Conclusion

(c)

INewmeyer should not be given as much credibility as he would have without the bias. $I_{I(33)}=0$

In the long run, this obviously makes it more difficult for Murray's argumentation process to reach the heuristic aim we have already referred to in (26).

\section{Conclusions: The Solution to (P1)}

However specific the above case study seems to be, it suggests generalizable insights that go beyond the limits of the case study. The conclusions to be drawn concern the nature of the notion of 'fallacy' in linguistic history writing.

After Hamblin pointed out the shortcomings of the traditional approach that assumed fallacies to be arguments (in our sense, inferences) which seem to be valid while they are 
not, the dominating approaches in the literature depart from this definition. ${ }^{28}$ Rather than deductive validity, some kind of 'correctness' works as the point of reference. Fallacies are considered in some sense 'incorrect', while they 'seem' to be 'correct'. ${ }^{29}$ In addition, they are also 'deceptive' in that through their seemingly convincing nature they mislead the recipient. Thus, three questions arise:
(a) What does it mean that fallacies 'seem' to be 'correct'?
(b) What does it mean that fallacies are still 'incorrect'?
(c) What does it mean that fallacies are 'deceptive' in that despite their incorrectness they may be convincing?

Any approach to fallacy is expected to explicate the vague notions 'seem', 'correct', 'incorrect' and 'deceptive' within the framework chosen. ${ }^{30}$ Let us see what explications of the notions in (34) the application of the p-model to the analyses we have carried out in Sect. 3 suggests.

Our answer to (34)(a) says that basically, fallacious stages in an argumentation process consist of sequences of inferences whose structure does not differ from the patterns of plausible inferences: for example, from plausible modus ponens, reduction or analogical inference etc., which are effective tools of problem solving used very often in everyday argumentation, as well as in scientific inquiry. Against this background, we will answer (34)(a) by differentiating between two senses of 'correctness'. The first is:

$$
\begin{aligned}
& \text { A stage of a plausible argumentation process is correct, if it consists of inferences conforming to } \\
& \text { the patterns of plausible inferences whose conclusions have a positive plausibility value. }
\end{aligned}
$$

However, in the p-model the point of reference is the heuristic aim of the problem solving process (primarily the solution or the resolution of a p-problem). Thus, in the second sense we replace 'correct' by 'effective' in the following way:

A stage of a plausible argumentation process is effective, if it
(a) consists of plausible inferences which are correct in the sense of (35), and
(b) contributes to reaching the heuristic aim of a given cycle or of the whole argumentation process.

Then, the explication of 'seem' presents itself straightforwardly:

(37) A stage of a plausible argumentation process seems to be correct, if the inferences in such a stage

(a) do conform to the patterns of plausible inferences, but

(b) have conclusions which are implausible or of neutral plausibility (in the sense of (1)).

\footnotetext{
28 See footnote 9.

29 According to Hansen's (2002: 152) generalization, “a fallacy is an argument that appears to be a better argument of its kind than it really is".

${ }^{30}$ We use the term 'explicate' as it is used in the philosophy of science: the substitution of a vague term by a more precise one.
} 
In other words: according to (37), since the structure of the inferences conforms to the patterns of plausible inferences, the inferences at issue would be correct, if the premises could support the conclusion-which, however, they cannot. This was the case with the inferences analyzed in Sect. 3.

As regards (34)(b), the p-model explicates 'incorrectness' in two senses as well:

(38) A stage of a plausible argumentation process is incorrect, if it consists of inferences which do not conform to the patterns of plausible inferences.

Cases to which (38) applies are no fallacies - they may be errors of different kinds. We explicate 'incorrect' in the second sense as 'ineffective' in (39):

(39) A stage of a plausible argumentation process is ineffective, if it

(a) consists of plausible inferences which seem to be correct in the sense of (37), and

(b) prevents a given cycle or the whole of the argumentation process from reaching its heuristic aim.

At this point, (39)(b) appears to correspond to our working definition (D), which turns out to have been too narrow and therefore no longer acceptable. It cannot capture what a fallacy amounts to, because, as a result of the findings of Sect. 3, it became merely one component of the definition of ineffectiveness. However, although (39) comprises our explication of 'correct', 'seem' and 'incorrect', we have still not obtained a more adequate definition of 'fallacy' than (D) has been, because our answer to (34)(c) is still missing. So, we turn to (34)(c).

As we have seen in Sect. 3, the failure of an argumentation stage to further the problem solving process is triggered by the interaction of factors rooted in the particular properties of the inferences: these factors are primarily the semantic relations in the premises, the source of the plausibility of the premises, and the latent background assumptions. These factors may, but need not, be simultaneously present and interact. It is these factors in which the 'deceptiveness' of fallacies is rooted.

The deceptiveness of fallacies is an intricate problem primarily because the literature has neglected it (see Walton 2010: 179). The p-model answers (34)(c) tentatively by pointing out that the deceptive nature of fallacies is rooted in the circumstance that the inferences in a fallacious argumentation stage have the same structure as plausible inferences, whereby the semantic relations in the premises, the latent background assumptions and the reliability of the sources may be interpreted differently. For example, as our analyses in Sect. 3.2 have witnessed, the recipient cannot decide immediately and with certainty whether a given relation is relevant or not; or exactly what premise is missing as a latent background assumption; or how reliable the direct source of the plausibility value of a premise is and, as a result, how high the latter's plausibility can be estimated. With respect to these factors there may be several options. The examples we have analyzed in Sect. 3 witness that due to the fact that there are several options, fallacies may 'deceive' the recipient by suggesting, for example, that the semantic relation between the two clauses of a premise is based on relevance, whereas it is not; or that the direct source of the plausibility value of a premise is reliable while its reliability is not sufficient for the assignment of a positive plausibility value to the statement. That is why it is easy to interpret the premises - which are the indirect source of the conclusion-mistakenly in such a way that they support the positive plausibility value of the conclusion, whereas they can assign it only neutral plausibility. In the extreme case, of course, there may be only a minimal difference 
between the neutral plausibility value and positive but low plausibility. Accordingly, we obtain:

(40) A stage of a plausible argumentation process is deceptive, if it includes inferences

(a) whose structure conforms to the patterns of plausible inferences; and

(b) in which there is more than one option to interpret the semantic relations within the premises or between the premises and the conclusion; or

(c) in which there is more than one option to identify a missing premise of an enthymematic plausible inference with a possible latent background assumption; or

(d) in which the reliability of the direct source of the plausibility value of a premise and, as a result, the latter's plausibility cannot be estimated with certainty; and

(e) which, due to (b), (c) and (d), suggest that the heuristic aim of the argumentation process can be reached because the plausibility value of the conclusion is at least minimally higher than neutral plausibility.

In sum: our train of thought boils down straightforwardly to the following solution to (P1), which presupposes the replacement of (D) by (37), (39) and (40) restricted to the case study in Sect. 3:

(SP1) (a) There are fallacies based on ad hominem argumentation and false analogy in the historiography of generative linguistics

(b) In general, in the historiography of generative linguistics, argumentation stages based on ad hominem and analogical inferences are fallacious, if they

(i) are ineffective in the sense of (39);

(ii) seem to be correct in the sense of (37); and

(iii) are deceptive in the sense of (40).

(c) In particular,

(i) ad hominem inferences as analyzed in Sect. 3 have a premise which attributes a 'negative' property to the person attacked;

(ii) false analogy as discussed in Sect. 3 is an inference following the pattern in (14);

(iii) the heuristic aim that could not be reached was finding the solution to the p-problem of p-incompleteness; and

(iv) in the fallacious argumentation stages of the plausible argumentation process at issue several types of inference interact.

Since (SP1) has been based merely on a limited case study, the question arises as to what extent and in what way it can be generalized to other fields of history writing which, similarly to the historiography of generative linguistics, also have been charged with being biased or fallacious. Answering this question by a series of further case studies would lead to valuable findings. Namely, once we have succeeded in revealing the very nature of fallacies in the historiography of different branches of the human sciences and learned how to identify them, we will be able to set up the argumentation strategies that serve their avoidance.

Acknowledgements Open access funding provided by University of Debrecen (DE).

Open Access This article is distributed under the terms of the Creative Commons Attribution 4.0 International License (http://creativecommons.org/licenses/by/4.0/), which permits unrestricted use, distribution, and reproduction in any medium, provided you give appropriate credit to the original author(s) and the source, provide a link to the Creative Commons license, and indicate if changes were made. 


\section{References}

Arens, H. (1969). Sprachwissenschaft: Der Gang ihrer Entwicklung von der Antike bis zur Gegenwart. Freiburg \& München: Alber.

Benfey, T. (1869). Geschichte der Sprachwissenschaft und orientalischen Philologie in Deutschland seit dem Anfange des 19. Jahrhunderts, mit einem Rückblick auf die früheren Zeiten. München: J.G. Cotta (Repr. New York: Johnson, 1965).

Butterfield, H. (1931). The whig interpretation of history. London: Bell.

Chomsky, N. (1957). Syntactic structures. The Hague: Mouton.

Chomsky, N. (1975). The logical structure of linguistic theory. New York: Plenum.

Chomsky, N. (2000). New horizons in the study of language and mind. Cambridge: MIT Press.

Copy, I., \& Burgess-Jackson, K. (1992). Informal logic. New York: Macmillan.

Delbrück, B. (1880). Einleitung in das Sprachstudium: Ein Beitrag zur Geschichte und Methodik der vergleichenden Sprachforschung. Leipzig: Breitkopf \& Härtel.

Griffith, B. C., \& Mullins, N. C. (1972). Invisible colleges: Small, coherent groups may be the same throughout science. Science, 177, 959-964.

Guarini, M. (2004). A defence of non-deductive reconstructions of analogical arguments. Informal Logic, 24, 153-168.

Hamblin, C. L. (1970). Fallacies. London: Methuen.

Hansen, H. V. (2002). The straw thing of fallacy theory: The standard definition of fallacy. Argumentation, 16, $133-155$.

Hitchcock, D. (1998). Does the traditional treatment of enthymemes rest on a mistake? Argumentation, 12, 15-37.

Hitchcock, D. (2017). On reasoning and argument: Essays in informal logic and on critical thinking. Cham: Springer.

Joseph, J. E. (1995). The structure of linguistic revolutions. Historiographia Linguistica, 22, 379-399.

Kertész, A. (2012). The 'Galilean Style in Science' and the inconsistency of linguistic theorising. Foundations of Science, 17, 91-108.

Kertész, A. (2017). The historiography of generative linguistics. Tübingen: Narr Francke Attempto.

Kertész, A., \& Rákosi, Cs. (2009). Cyclic vs. circular argumentation in the conceptual metaphor theory. Cognitive Linguistics, 20, 703-732.

Kertész, A., \& Rákosi, Cs. (2012). Data and evidence in linguistics: A plausible argumentation model. Cambridge: Cambridge University Press.

Kertész, A., \& Rákosi, Cs. (Eds.). (2014a). The p-model of data and evidence in linguistics. In The evidential basis of linguistic argumentation (pp. 15-48). Benjamins: Amsterdam \& Philadelphia.

Kertész, A., \& Rákosi, Cs. (Eds.). (2014b). The evidential basis of linguistic argumentation. Benjamins: Amsterdam \& Philadelphia.

Koerner, E. F. K. (1983). The Chomskyan 'revolution' and its historiography: A few critical remarks. Language \& Communication, 3, 147-169.

Koerner, E. F. K. (2006). The development of linguistic historiography-History, methodology, and present state. In S. Auroux, E. F. K. Koerner, H.-J. Niederehe, \& K. Versteegh (Eds.), History of the language sciences. An international handbook on the evolution of the study of language from the beginnings to the present (pp. 2802-2820). Berlin \& New York: de Gruyter.

Lakoff, R. (1989). The way we were; or; the real truth about generative semantics: A memoir. Journal of Pragmatics, 13, 939-988.

Łukasiewicz, J. (1970 [1912]). Creative elements in science. In: J. Łukasiewicz (Ed.), Selected works (pp. 12-44). Amsterdam: North Holland.

Macagno, F., \& Walton, D. (2018). Practical reasoning arguments: A modular approach. Argumentation. https:// doi.org/10.1007/s10503-018-9450-5.

Martin-Nielsen, J. (2010). Redifining what matters: Syntactic explanation in American linguistics, 1955-1970. The Canadian Journal of Linguistics, 55, 331-358.

Murray, S. O. (1989). Recent studies of American linguistics. Historiographia Linguistica, 16, 149-171.

Murray, S. O. (1994). Theory groups and the study of language in North America. A social history. Amsterdam \& Philadelphia: Benjamins.

Newmeyer, F. J. (1980). Linguistic theory in America. The first quarter century of transformational generative grammar. New York: Academic Press.

Newmeyer, F. J. (1986). The politics of linguistics. Chicago: Chicago University Press.

Newmeyer, F. J. (2014). Getting the word out: The early generativists' multi-pronged efforts to diffuse their ideas. Language, 90, 241-268. 
Nielsen, J. (2010). Private knowledge, public tensions: Theory commitment in postwar American linguistics. $\mathrm{PhD}$ Dissertation, University of Toronto.

Polya, G. (1948). How to solve it. Princeton: Princeton University Press.

Polya, G. (1954). Patterns of plausible inference. London: Oxford University Press.

Rapp, C. (2010). Aristotle's rhetoric. Stanford Encyclopedia of Philosophy. http://plato.stanford.edu/entries/arist otle-rhetoric/. Accessed July 12, 2018.

Rescher, N. (1976). Plausible reasoning. Assen \& Amsterdam: Van Gorcum.

van Eeemeren, F., \& Grootendorst, R. (2004). A systematic theory of argumentation. The pragma-dialectical approach. Cambridge: Cambridge University Press.

van Eemeren, F., Garssen, B., \& Meuffels, B. (2009). Fallacies and judgments of reasonableness. Empirical research concerning the pragma-dialectical diskussion rules. Dordrecht: Springer.

Waller, B. N. (2001). Classifying and analyzing analogies. Informal Logic, 21, 199-218.

Walton, D. (1995). A pragmatic theory of fallacy. Tuscaloosa: The University of Alabama Press.

Walton, D. (1996). Fallacies arising from ambiguity. Dordrecht: Kluwer.

Walton, D. (1998). Ad hominem arguments. Tuscaloosa: The University of Alabama Press.

Walton, D. (2006). Fundamentals of critical argumentation. New York: Cambridge University Press.

Walton, D. (2010). Why fallacies appear to be better arguments than they are. Informal Logic, 30, 159-184.

Walton, D. (2013a). Relevance in argumentation. New York: Routledge.

Walton, D. (2013b). Methods of argumentation. Cambridge: Cambridge University Press.

Walton, D., Reed, C., \& Macagno, F. (2008). Argumentation schemes. Cambridge: Cambridge University Press.

Publisher's Note Springer Nature remains neutral with regard to jurisdictional claims in published maps and institutional affiliations.

András Kertész is Professor of Linguistics at the University of Debrecen (Hungary). He was elected as a Member of the Hungarian Academy of Sciences in 2001 and of Academia Europaea (London) in 2014. His main fields of research are the philosophy of linguistics and theoretical linguistics. He published 12 monographs, 9 collections of papers and about 150 articles. His books include Cognitive Semantics and Scientific Knowledge: Case Studies in the Cognitive Science of Science (Amsterdam: Benjamins, 2004), Philosophie der Linguistik. Studien zur naturalisierten Wissenschaftstheorie (Tübingen: Narr, 2004), Data and Evidence in Linguistics: A Plausible Argumentation Model (Cambridge: Cambridge University Press, 2012; co-author: Csilla Rákosi) and The Historiography of Generative Linguistics (Tübingen: Narr Francke Attempto, 2017). 